\title{
Revisiting Discourse in \\ Deaf Studies in Germany
}

Rathmann \& Geissler

Humboldt-Universität zu Berlin

2018 Deaf Studies Conference

Gallaudet University

November 1-3, 2018

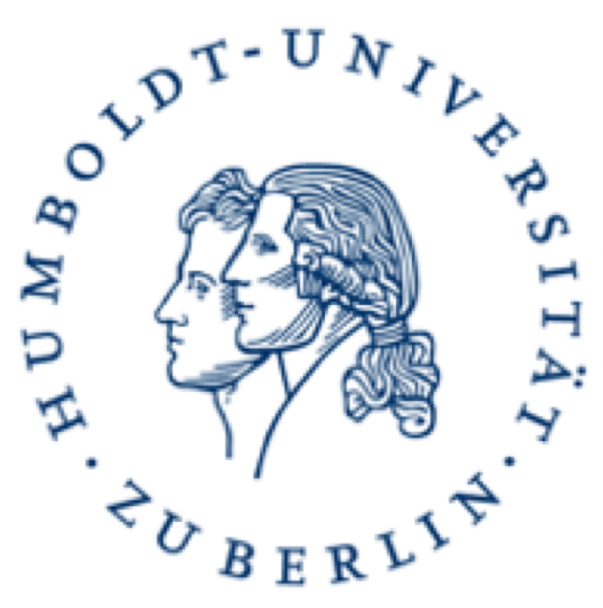




\section{Outline}

1. Background

2. Research Question

3. Methodology

4. Findings

5. Discussion and Further Steps 
1. Background: Deaf Studies in Germany

- Stakeholders

i. Deaf (individuals and groups)

ii. Practioners (teachers, interpreters etc.)

iii. Researchers

- Institutions

i. Universities (BA- \& MA-programs, PhD disseration projects)

ii. Associations (e.g. GGKG e.V., KUGG e.V.)

iii. Minority associations (ethnicity, language, religion)

iv. Professional associations

- History

i. Legal Recognition of German SL (2002)

ii. Identity Constructions within Deaf Studies

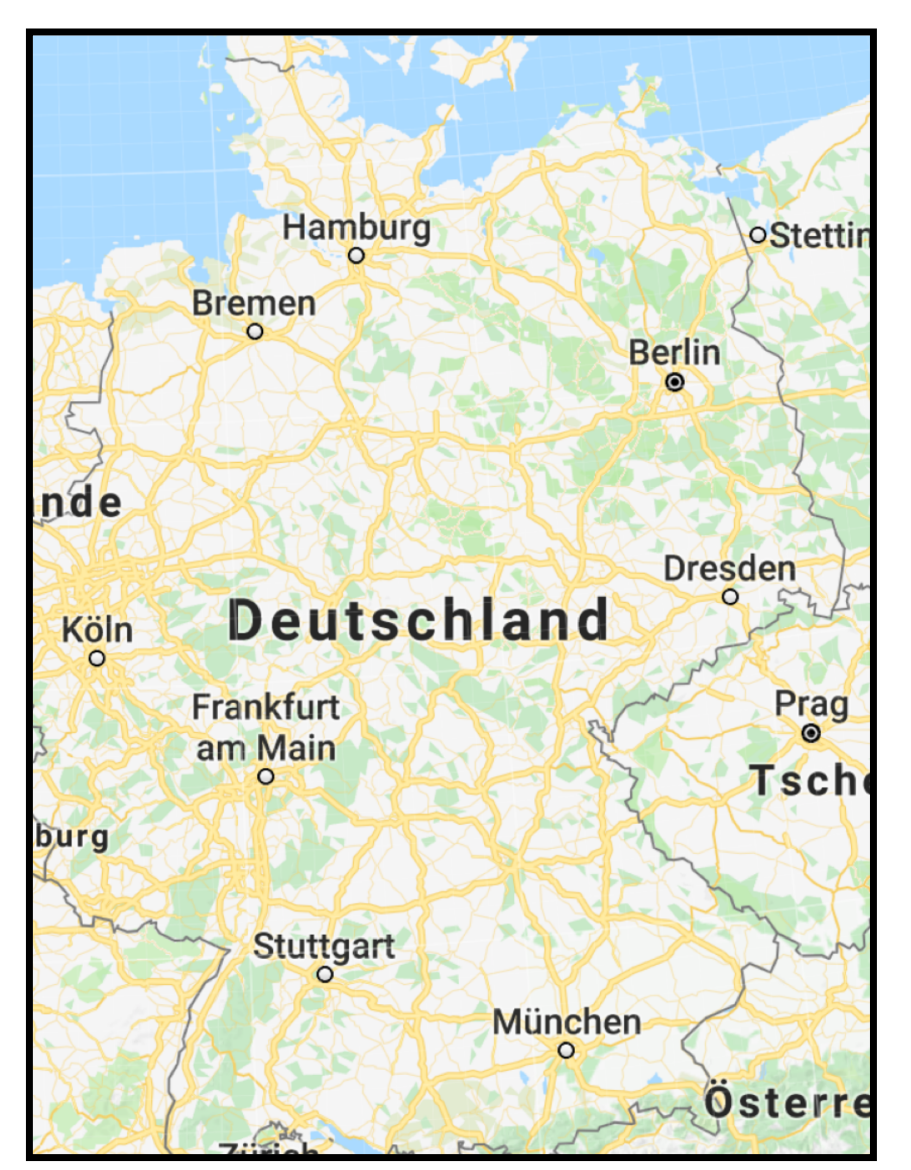


2. Research Question

Discourse of Deaf Studies in Germany from the transformational perspective

- Emergence of Deaf Studies (from diachronic standpoint of view)

- State of Art in Deaf Studies (from synchronic standpoint of view)

- Interdisciplinary of Deaf Studies and collaboration with stakeholders

- Use of Languages, Modalities and Media

- Intersectionality between Deaf Studies and Disability Studies 


\section{Methodology: Bilingual Online Survey (June - September 2018; open questions)}

(a) Gender

(b) Hearing Status
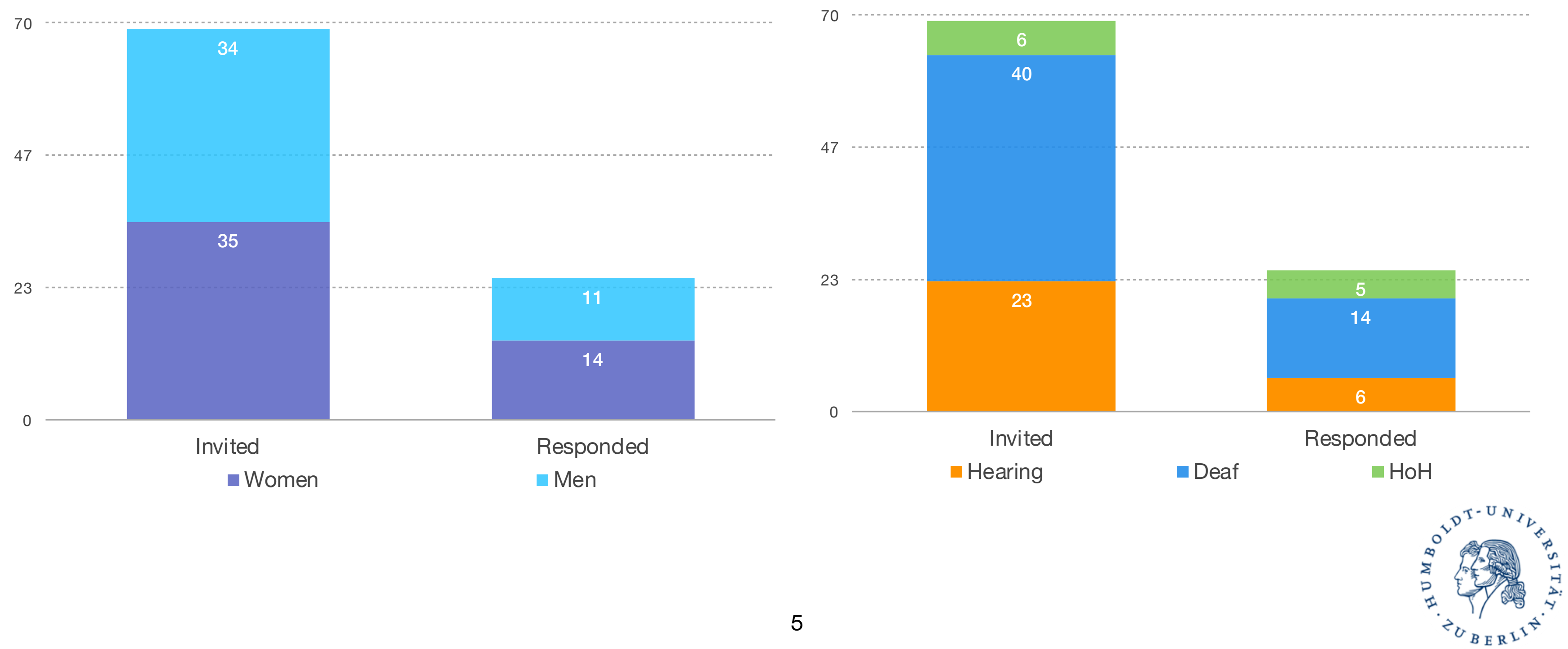


\section{Methodology: Bilingual Online Survey (June - September 2018; open questions)}

(c) Position

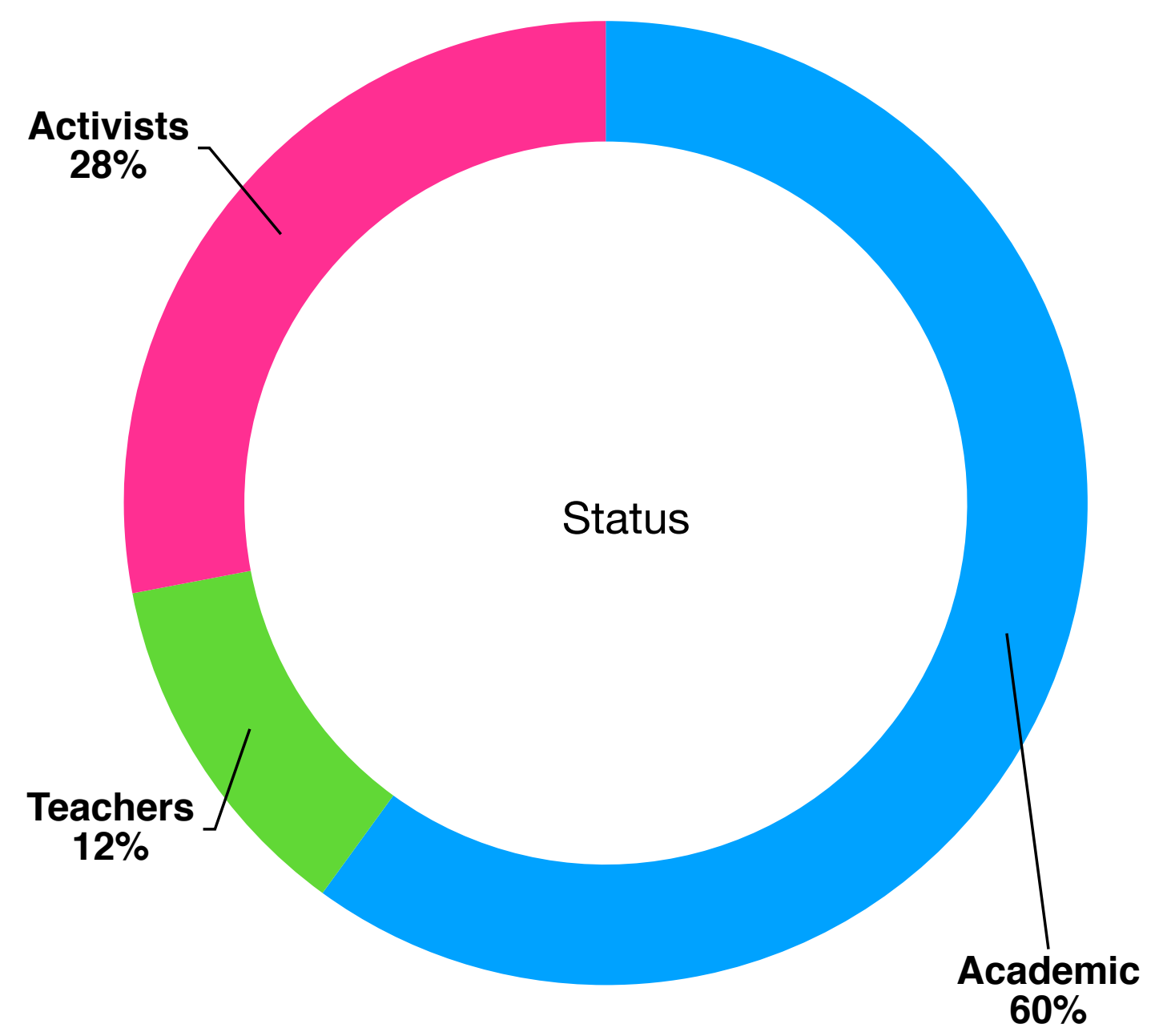

\section{(d) Origin}

Participants with immigration background

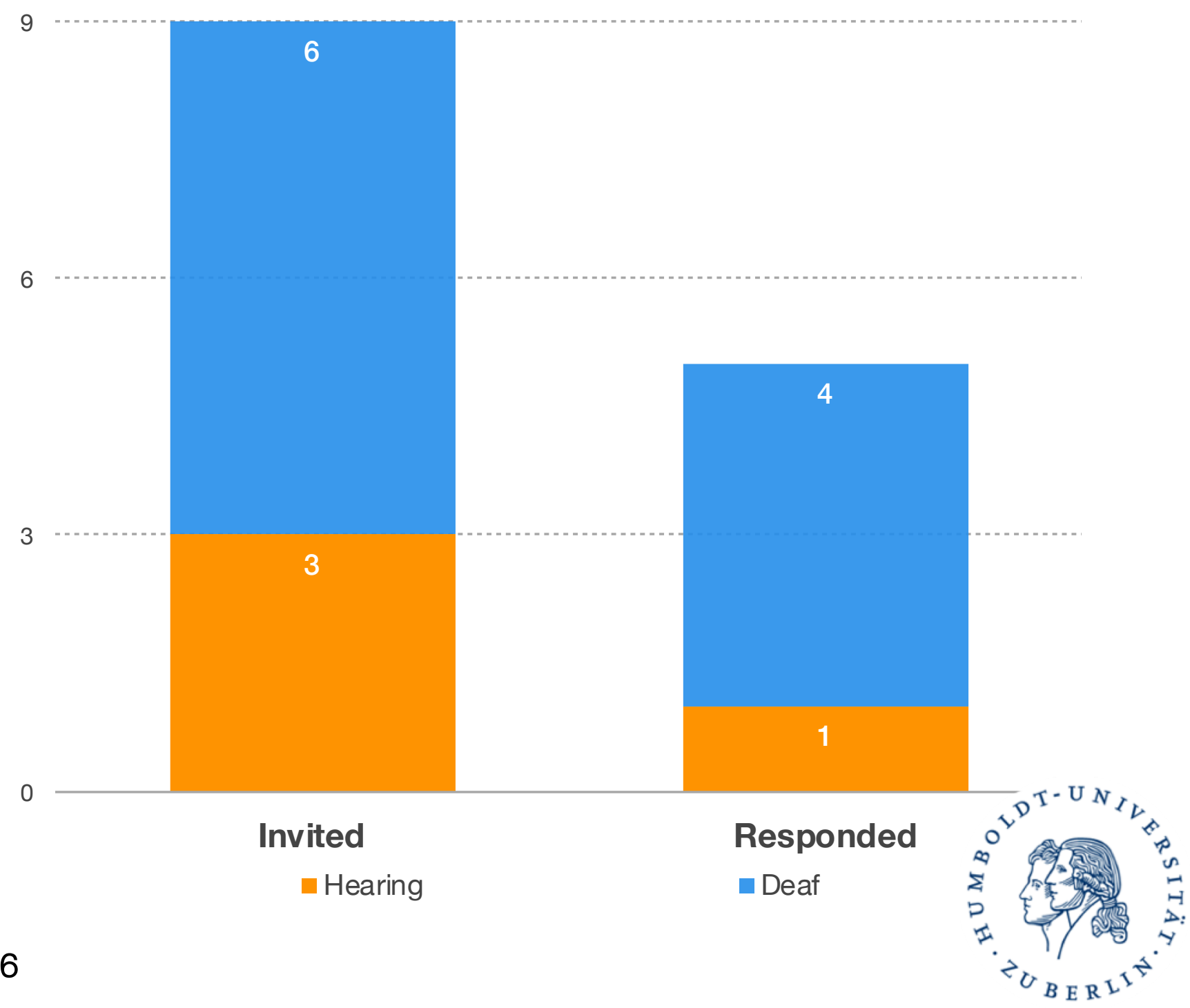


3. Methodology: Bilingual Online Survey (June - September 2018; open questions)

1. Data Collection (Online)
2. Translations (DGS => German)
3. Content Analysis
4. Categorization (Two Rounds)
5. Translations (German => English)
Qualitative Approach
In line with Grounded Theory (Glaser \&
Strauss 1967/1998)
Methodological Limitations


4. Findings

4. 1. Languages and Modalities

- „DGS only“ <==> „German as an act of dominance"

- Use of Social Media, Conferences and Workshops

- Academic publications („Das Zeichen“ and dissertations)

$=>$ Definition of target groups (audience)

$=>$ Dissemination of knowledge

$\Rightarrow$ Accessibility and transparency 
4. Findings

4. 1. Languages and Modalities

"I often did not feel very welcome in the scientific community of Deaf Studies. I'm especially

remembering the welcoming speech by (person) at the conference (...).

There (person) represented a "DGS only" policy and dismissed interpreting in spoken languages as counterproductive: Interpretation as something she would rather not witness.

At that moment I thought that Deaf Studies wants to exclude hearing researchers and those in general who aren't excellent sign language users deliberately." 
4. Findings

4. 1. Languages and Modalities

"It would certainly be desirable, as an exchange between academics and nonacademics can always lead to empowerment, and the dissemination of research results, especially in minority research, should be an important part of research work." 
4. Findings

4. 1. Languages and Modalities

"In addition, the discourse is still influenced or co-determined by academic participants, some of whom have no access to sign language and deaf community and still write essays, as if they knew better. This complicates the discourse, because some deaf participants can not understand these due to language and cultural differences.The use of the German language as a discourse language for me is an act of paternalism and unsolicited empowerment of interpretive sovereignty in Deaf Studies." 
4. Findings

4. 1. Languages and Modalities

"The same applies to the scientific exchange, as it is not systematically networked in Germany at all levels and sometimes there are language barriers, since mastering the German Sign Language is not yet taken for granted for the scientific discourse and by that some deaf researchers are excluded." 
4. Findings

4. 1. Languages and Modalities

- Insecurities

- Misunderstandings

- Hostile Environment

- Exclusion 
4. Findings

4. 1. Languages and Modalities

- Insecurities

- Misunderstandings

- Hostile Environment

- Exclusion

Transformation in Deaf Studies

=> largely determined by language ideology, language access and power within academic

\section{communities}


4. Findings

4. 2. Topics to be pursued in Deaf Studies

- Ethnographic studies (language use, cultural practice, diversity and history relevance)

- Intersectionality (discrimination and oppression experiences)

- Interface between Deaf Studies and Disability Studies (e.g. CRPD, inclusion etc.)

- Postcolonial Studies 
4. Findings

4. 2. Topics to be pursued in Deaf Studies

"German-speaking countries empirical social studies and linguistics seem dominant to me. I have rarely noticed the reference back to cultural studies theories in Germany, regarding that I rather think of English Deaf Studies." 
4. Findings

4. 2. Topics to be pursued in Deaf Studies

"I am missing an (official!) implementation of Deaf Studies in other relevant degree programs such as linguistics, education for the Deaf, Disability Studies, medicine and other interdisciplinary subjects." 
4. Findings

4. 2. Topics to be pursued in Deaf Studies

"I see the combination of theory and practice as a great opportunity to make the field of Deaf Studies more present in public, too. Ethnographic field research in particular can make its contribution here." 
4. Findings

4. 2. Topics to be pursued in Deaf Studies

"In my opinion, emphasis (of Deaf Studies) is often on differentiation from Disability

Studies and the establishment of an independent discipline." 
4. Findings

4. 2. Topics to be pursued in Deaf Studies

"Both studies (Deaf Studies and Disability Studies) should be placed separately and form an independent perspective on various research topics. An interdisciplinary productive exchange on an equal footing forms a productive basis for both studies." 
4. Findings

4. 2. Topics to be pursued in Deaf Studies

"Deaf studies should urgently become part of disability studies, on the one hand because there are parallels, but also because in the series of disability studies there is a partial (and unexpressed) thinking about deafness as a deficit.

Likewise, an further opening of deaf studies for people without DGS skills (both hearing and hearing impaired) would be desirable." 
4. Findings

4. 2. Topics to be pursued in Deaf Studies

"A meta-level discourse has developed predominantly in the academic field, which now reflects and discusses the contents of Deaf Studies.

This academicization process is still in development in Germany and is largely influenced by the Anglo-Saxon discourse." 
4. Findings

4. 2. Topics to be pursued in Deaf Studies

"For deaf people, the key points seem to be clarified (e.g. Deaf Studies Encyclopedia 2015; Mission Statement in Fischer et al. 2009), but other people still doubt them. So far, however, no alternative convincing concepts have been offered, but only discussion points which I can't always retrace." 
4. Findings

4. 2. Topics to be pursued in Deaf Studies

- Ethnographic studies (language use, cultural practice, diversity and history relevance)

- Intersectionality (discrimination and oppression experiences)

- Interface between Deaf Studies and Disability Studies (e.g. CRPD, inclusion etc.) - Postcolonial Studies 
4. Findings

4. 2. Topics to be pursued in Deaf Studies

- Ethnographic studies (language use, cultural practice, diversity and history relevance)

- Intersectionality (discrimination and oppression experiences)

- Interface between Deaf Studies and Disability Studies (e.g. CRPD, inclusion etc. )

- Postcolonial Studies

Transformation in Deaf Studies

(a) Close space $=>$ public space (b) Positionality of Deaf Studies (c) Power 
4. Findings

4. 3. Methodology and application

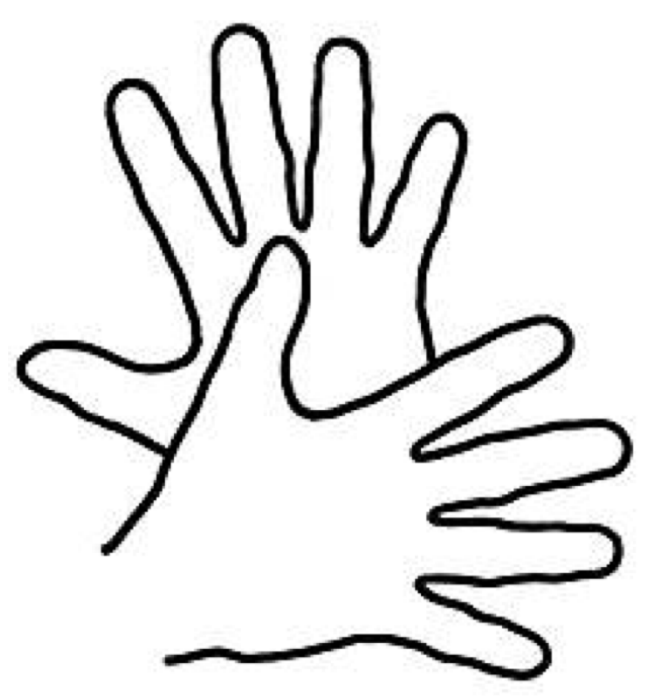

- Deaf Education

- Sign Language Education

- Interpreting

- Mental Health

- Participation in Society 
4. Findings

4. 3. Methodology and application

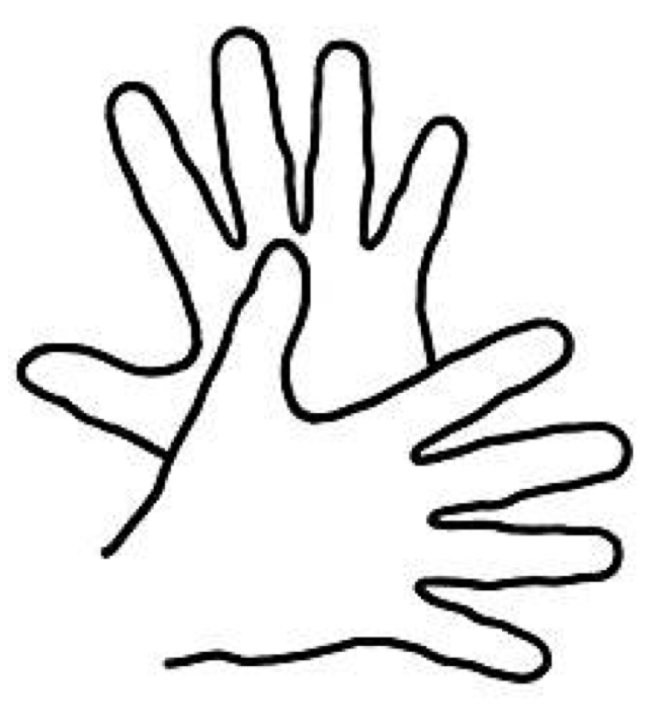

"There is certainly still a lot of catching up to do in other areas, such as psychology and education, where research has traditionally been carried out more by hearing scientists, who may feel less connected to deaf studies." 
4. Findings

4. 3. Methodology and application

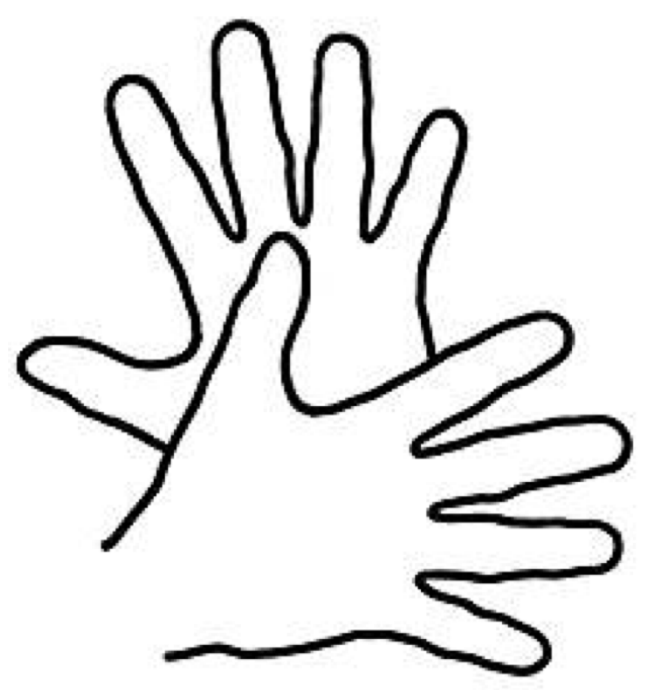

"One should rather turn away from the political work to the deaf studies in a scientific sense. The mixture of research and political activity also poses ethical dilemmas. The own political conviction must be clearly separated from the scientific work to ensure a neutral and objective working attitude." 
4. Findings

4. 3. Methodology and application

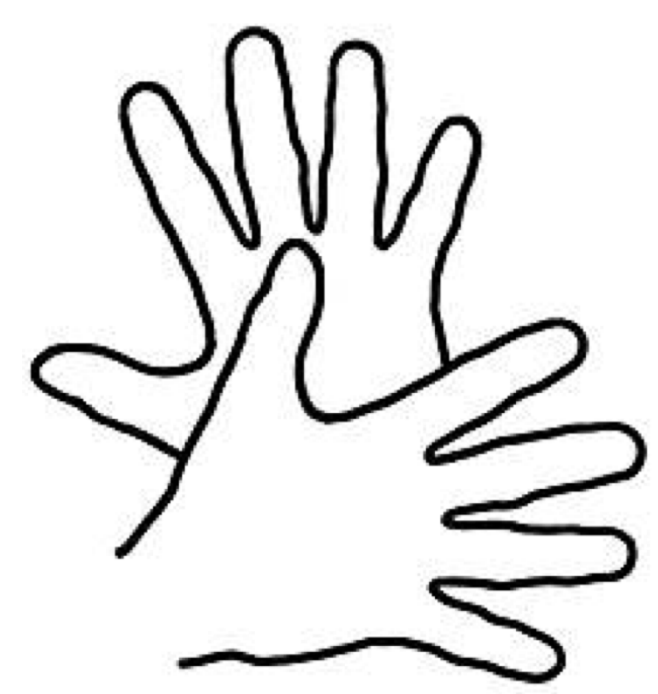

"So far, the discourse regarding deaf studies has mainly taken place in spoken languages, which is a clear contradiction for me. And again, we see the inner conflict between research and political views, which makes a separation of the two indispensable. Of course, we also have to be aware that in the deaf studies we are dealing with a minority and therefore in cooperations work together with hearing researchers, although very few are actually fluent in a sign language." 
4. Findings

4. 3. Methodology and application

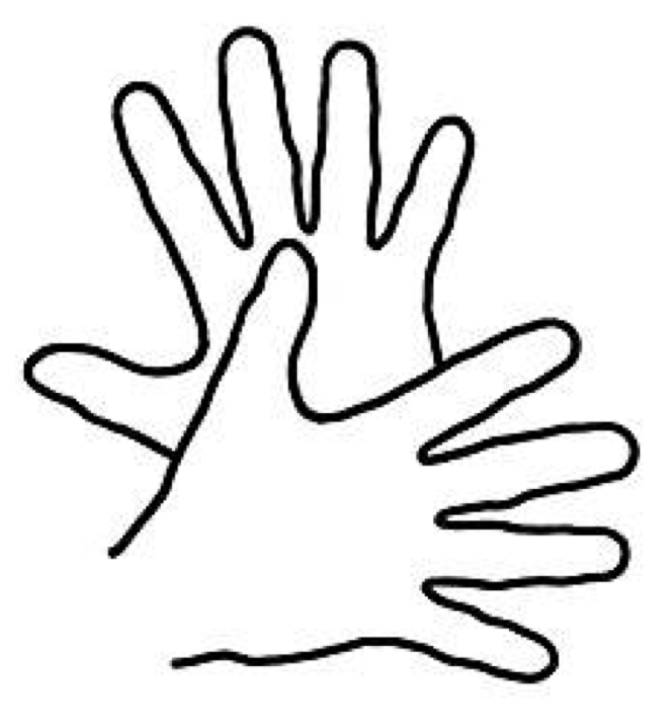

- Deaf Education

- Sign Language Education

- Interpreting

- Mental Health

- Participation in Society 
4. Findings

4. 3. Methodology and application

- Deaf Education

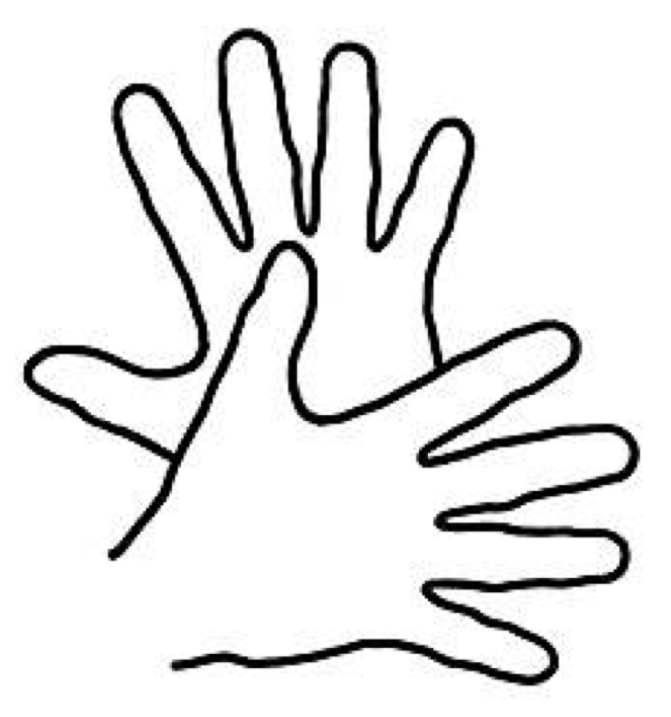

- Sign Language Education

- Interpreting

- Mental Health

- Participation in Society

Transformation in Deaf Studies

(a) Which agenda? Is such a separation possible? Impact on other areas?

(b) Use of scientific methodology

(c) Language $=>$ ethics in research 
5. Discussion and Further Steps

Discourse of Deaf Studies in Germany from various transformational perspectives

- Diachronic and synchronic perspectives

- Interdisciplinary of Deaf Studies, collaboration with stakeholders and research ethics

- Use of Languages, Modalities and Media

- Intersectionality between Deaf Studies and Disability Studies 